\title{
Will a New Little Ice Age Begin in the Next Few Decades?
}

\author{
Maxim Gennadievich Ogurtsov ${ }^{1}$, Markus Lindholm ${ }^{2} \&$ Risto Jalkanen ${ }^{2}$ \\ ${ }^{1}$ Laboratory of cosmic rays, Ioffe Physical-Technical institute, Russian Federation \\ ${ }^{2}$ Finnish institute for forestry research (Metla), Finland \\ Correspondence: Maxim Gennadievich Ogurtsov, Laboratory of cosmic rays, Ioffe Physical-Technical institute, \\ St. Petersburg 194 021, Polytechnicheskaya 26, Russian Federation. E-mail: maxim.ogurtsov@mail.ioffe.ru
}

Received: March 5, 2013 Accepted: April 11, 2013 Online Published: May 2, 2013

doi:10.5539/apr.v5n3p70 URL: http://dx.doi.org/10.5539/apr.v5n3p70

\begin{abstract}
Recently, Abdussamatov (2012) claimed that a period of deep $\left(>1.0^{\circ} \mathrm{C}\right)$ global cooling-a new Little Ice Age-will begin soon. The question of future climate variability is not merely of scientific interest but of huge significance for the wellbeing of mankind. We examine here in detail the statements of Abdussamatov (2012), which have received appreciable response in the popular media. We revealed that the prediction of a significant drop in global temperature in the next few decades has poor scientific basis. We conclude that this cooling projection is based on: (a) a number of either arbitrary or erroneous assumptions, (b) lack or ignorance of experimental data, (c) and a more or less flawed forecasting technique. Possible scenarios of future climatic variation are discussed.
\end{abstract}

Keywords: TSI desrease, Little Ice Age, global warming

\section{Introduction}

Most life forms on Earth depend on the Sun's energy. The history of mankind covers severe examples of the vulnerability of human society of this dependence. Past famines were frequently related with severe climatic events, which in turn are often connected to periods of unusual solar activity. The presence (as well as absence) of a link between the Sun's activity and the Earth's climate has been claimed in numerous studies and consequently the possibility of solar contribution to global climatic change is at present actively debated. No doubt new advancements in our current understanding of the behavior of climate during the most recent past as well as the coming decades is of great importance for the future of human well-being. The IPCC has assessed that global warming is caused mainly by anthropogenic emission of greenhouse gases and forecasts further increase of global temperature by $2.8-6.4{ }^{\circ} \mathrm{C}$ in the $21^{\text {st }}$ century (IPCC, 2007). Some predictions, such as those by Abdussamatov $(2007,2012)$ are in sharp disagreement with the projected warming (IPCC, 2007). Abdussamatov's $(2007,2012)$ conclusions are based on the data of total solar irradiance (TSI) measurement predicting global cooling and the beginning of a new Little Ice Age in the first part of the current century. This theory relies on the following chain of reasoning:

(a) TSI permanently decreases (has a downward trend) during the last three solar cycles;

(b) the decrease is caused by a bi-centennial cycle of TSI;

(c) the decrease of TSI will continue during the next few decades and thus its value will drop down to 1359.5 $\pm 2.4 \mathrm{~W} \mathrm{~m}^{-2}$ at $\mathrm{AD} 2042.9 \pm 1.8$; and

(d) as a result the Earth's temperature will fall by ca. $1.2{ }^{\circ} \mathrm{C}$ by the mid- $21^{\text {st }}$ century and a slow warming will start only after AD 2100 (see figure at http://www.gao.spb.ru/english/astrometr/index1_eng.html).

This prediction does not take anthropogenic factors into consideration, neglecting the greenhouse effect. In the present work we examine the reality of these views as stated above.

\section{Long-Term Change of TSI and Its Further Projection}

Direct measurements of total solar irradiance (TSI) made outside the Earth's atmosphere began with the launch of satellite instruments in 1978. Generalization of the data, obtained in different space experiments and by means of different radiometers, has made it possible to construct three composite TSI series: the PMOD, the ACRIM and the IRMB composites (Figure 1). 


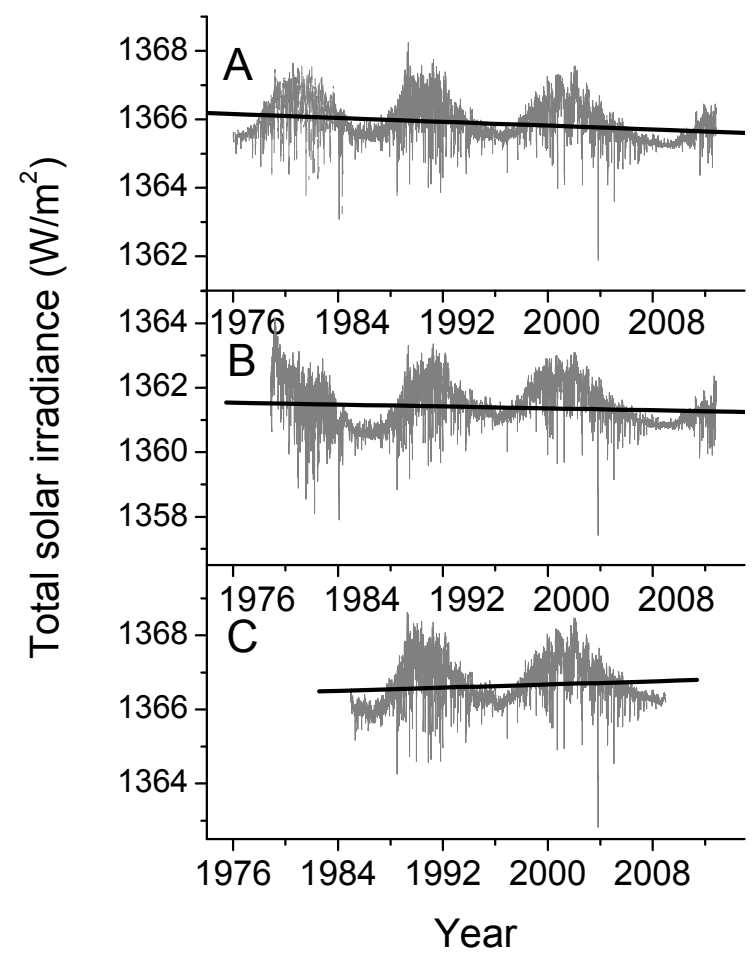

Figure 1. Total solar irradiance composites A-PMOD (Fröhlich, 2006, updated from ftp://ftp.pmodwrc.ch/pub/data/irradiance/composite/DataPlots/ext_composite_d41_62_1210a.dat)

B-ACRIM (Willson \& Mordvinov, 2003, updated from

http://www.acrim.com/RESULTS/data/composite/composite acrim 1105.rtf)

C - IRMB (Dewitte, Crommelynck, Mekaoui \& Joukoff, 2004, updated from

(http://remotesensing.oma.be/meteo/view/en/3385925-SARR.diarad.html)

Gray curves - the raw data, black lines - long-term linear trends

Evidently only PMOD composite shows a decrease of the mean TSI value, which is ca. $0.5 \mathrm{~W} \mathrm{~m}^{-2}$ through 1976-2012 (Figure 1) i.e. $0.14 \mathrm{~W} \mathrm{~m}^{-2} / 10$ year. Taking into account that according to Fröhlich (2009) the uncertainty of long-term TSI measurement during the minima of 1977, 1986, 1996 and 2008 reaches $0.10,0.01$, $0.10,0.16 \mathrm{~W} \mathrm{~m}^{-2}$ correspondingly, statistical significance of this trend does not appear reliable. The ACRIM series has practically no trend in 1978-2012 and the IRMB series has a weak upward trend in 1985-2008. Thus, an analysis of the tree available composite data sets does not allow us to make any conclusion about the long-term tendency of solar luminosity. The differences between the three composite series are currently actively debated (Lockwood \& Fröhlich, 2008; Fröhlich, 2011). It should be noted also, that the data obtained by the latest instrument, the Total Irradiance Monitor, have led the ACRIM team to the conclusion that the actual value of mean TSI is $4.6 \mathrm{~W} \mathrm{~m}^{-2}$ lower than previously measured (Kopp \& Lean, 2011). This testifies that uncertainty, related to the calibration of the instruments and their degradation over time, could reach a few $\mathrm{W} \mathrm{m}^{-2}$. Thus, some authors (Haigh, 2009; Mordvinov, 2010) believe that measurement uncertainty makes it practically impossible to establish the existence of any secular variation in solar luminosity during the last three cycles. Consequently the idea that the amount of solar radiation hitting the Earth is constantly decreasing since the end of the 70s (Abdussamatov, 2007, 2012) has only limited experimental support, at least at present. A quasi 11-year variation is the only cyclicity, the presence of which in TSI has been established absolutely reliably and unequivocally.

The theoretical basis for anticipating a decrease in solar luminocity during the last 35 years is not very solid either. Although we can note that some decline in Wolf number through the solar cycles 21-23 actually takes place, the relationship between time variations in sunspot number and solar irradiance has not been exactly established. This relationship is also likely to have a nonlinear character, i.e. the latest solar minimum in 2008-2009 was deeper and more prolonged than what have been observed for almost a century and it did not result in very low values of TSI (see Figure 1). Many long-term reconstructions of TSI have been obtained using the sunspot number data (e.g. Hoyt \& Schatten, 1993; Lean, Beer, \& Bradley, 1995; Solanki \& Fligge, 1999; 
Krivova, Balmaceda, \& Solanki, 2007), but they all are based on rather arbitrary assumptions and have only a hypothetical character. Thus, the downward tendency in Wolf number during the last three cycles does not automatically result in a corresponding trend in TSI. Moreover, even if some descending trend in TSI actually exists it can hardly be fully prescribed to a bicentennial periodicity. Indeed, long-term sunspot variability almost certainly has a bicentennial (170-270-year) mode - the cycle of Suess (de Vries). In addition it also has a century-type variation - the cycle of Gleissberg (55-135-year) and probably longer cycles, too. Furthermore, long-term variation of solar activity likely also includes a random component (Ogurtsov, 2009). For example the occurrence of grand minima and maxima most probably is a result of chaotic processes (Usoskin, 2008). Therefore the decline in TSI after the end of the $70 \mathrm{~s}$, if it actually takes place, could plausibly be a result of a combination of long-term variations of several types, both periodical and non-periodical. Summarizing all stated above, we can note that:

(a) it is impossible at present to speak about any long-term trend in TSI after the end of the 70s, because of disagreement between different composites and large experimental uncertainties;

(b) a link between long-term variations in Wolf number and solar luminosity remains unclear.

So, the statement of Abdussamatov (2012) that both bi-centennial and eleven-year cyclic variations of TSI and solar activity are synchronized and inter-correlated in both phase and amplitude is based on rather weak scientific evidence. Correspondingly the prediction of TSI for the next three cycles by Abdussamatov (2012) seems to be principally flawed and incorrect. Abdussamatov (2012) made the forecast using the following procedure: (a) take the PMOD series, (b) ascribe the descending tendency in the smoothed value of TSI in the minima between the cycles 21/22, 22/23 and 23/24 (see Fig. 1A) fully to a bi-centennial cycle and then (c) extrapolate the 200-year periodicity till the second part of the $21^{\text {st }}$ century. As described above this procedure seems to lack physical meaning. It is evident that if the other TSI composites (ACRIM or IRMB) had been used, the results would have been very different. Figures 1B and C show (see also Figure 1 from the web site http://www.pmodwrc.ch/pmod.php?topic=tsi/composite/SolarConstant for IRMB series till 2012) that in both of these data sets mean TSI during 2008-2010 is somewhat higher than during 1986-1988. Therefore, according to ACRIM and IRMB composites change of mean solar irradiance in the minima between the cycles $21 / 22,22 / 23$ and 23/24 does not produce any downward tendency.

\section{Long-Term Change in Global Climate and Its Further Projection}

The global temperature forecast of Abdussamatov (2012) is based on the assumption that all periods of significant climate changes found during the last several millennia were caused by bi-centennial quasi-periodic TSI variations. This supposition is not supported by the data of paleoclimatology. Seven modern reconstructions of the Northern Hemisphere temperature during the last millennium - based on tree-ring proxies after Briffa (2000) and Esper, Cook and Schweingruber (2002), non tree-ring proxy after Loehle (2007) and multi-proxies after Jones, Briffa, Barnett, \& Tett (1998), Mann, Bradley, and Hughes (1999), Crowley and Lowery (2001), and Moberg, Sonechkin, Holmgren, Datsenko, and Karlen (2005)-were analyzed here (Figure 2). 


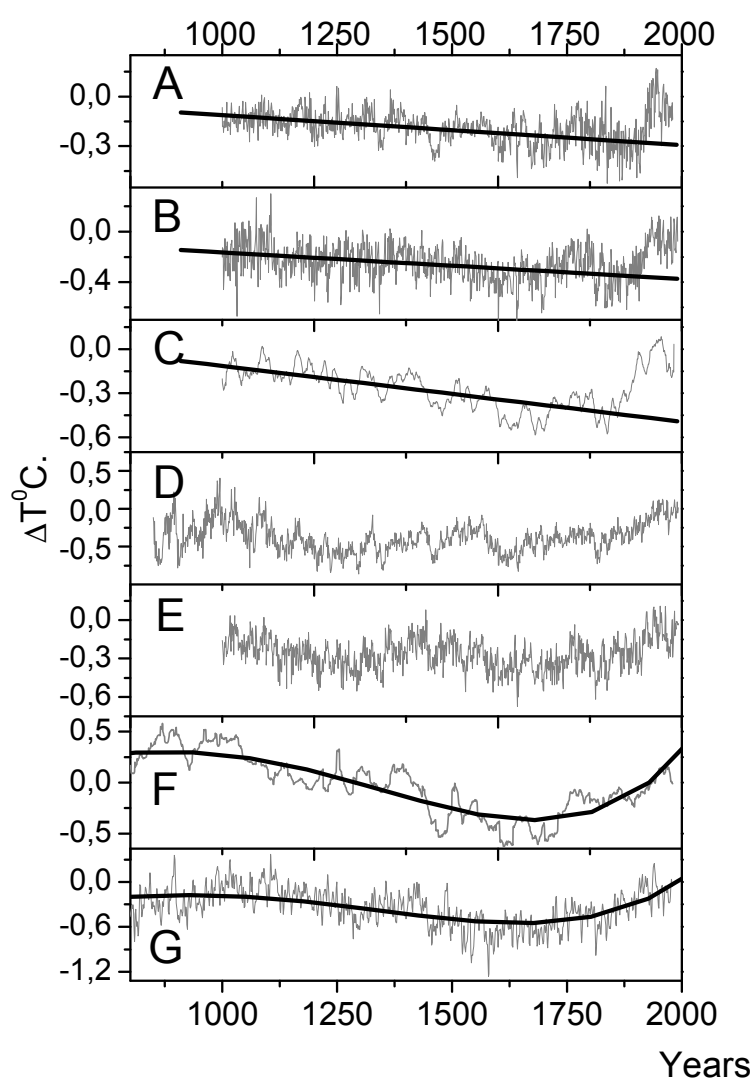

Figure 2. Reconstructions of the Northern Hemisphere temperature over the last 1-2 millennia

A - the multiproxy of Mann, Bradley, and Hughes (1999). B - the multiproxy of Jones, Briffa, Barnett and Tett (1998). C - the multiproxy of Crowley and Lowery (2001). D - the tree-ring proxy of Esper, Cook and Schweingruber (2002). E - the tree-ring proxy of Briffa (2000). F - the non tree-ring proxy of Loehle (2007). G - the multiproxy of Moberg, Sonechkin, Holmgren, Datsenko and Karlen (2005). All the data sets, with the exception of the series of Loehle (2007) and Moberg et al. (2005) were recalibrated by Briffa and Osborn (2005). Grey curves represent raw data. Thick black lines represent the calculated long-term tendencies.

A visual study of the series (Figure 2) indicates no distinct 200-year periodicity in the available temperature reconstructions. Instead large-scale long-term variability is dominated by linear trends (Figures 2A, B, C), multi-centennial cycles (Figures 2D, E) and millennium-long variations (Figures 2F, G). The Fourier spectra of these paleoreconstructions, calculated over AD 1000-1930-i.e. for a time interval prior to a possible strong anthropogenic impact-are plotted in Figure 3. 


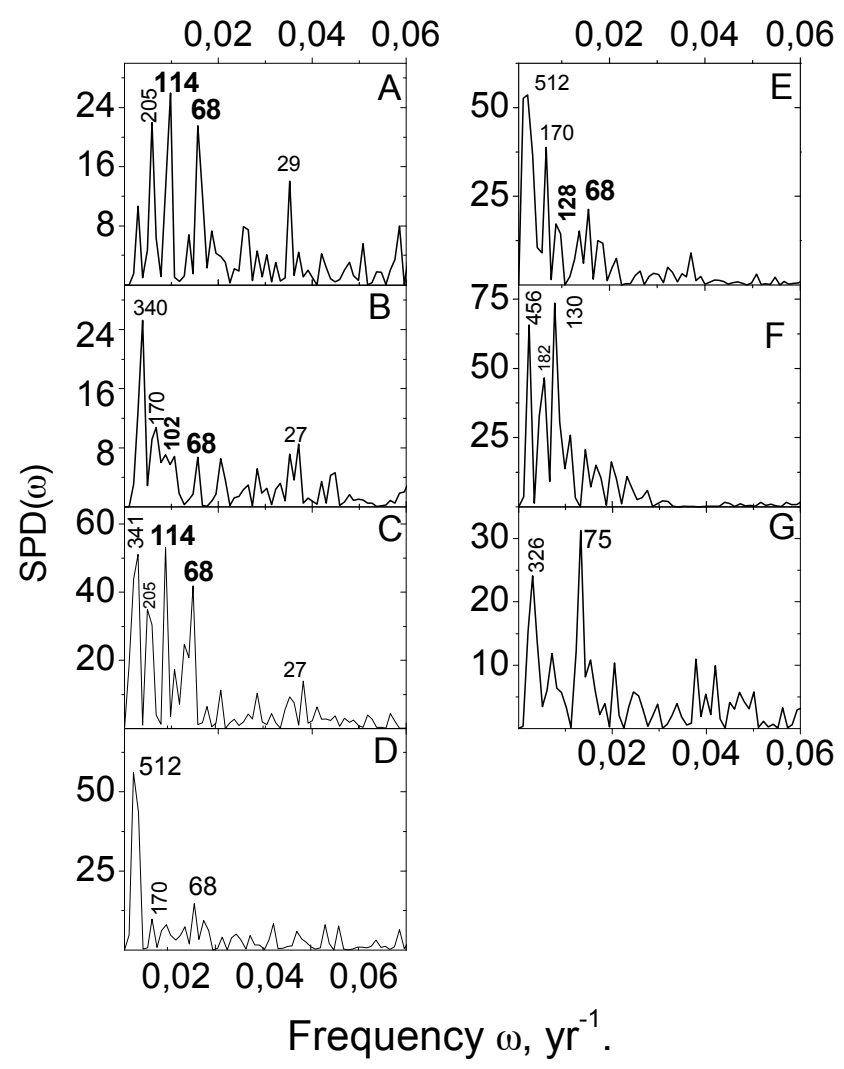

Figure 3. Fourier spectra of the temperature reconstructions

A - multiproxy of Mann, Bradley, and Hughes (1999) (linear trend removed), B - multiproxy of Jones, Briffa, Barnett, and Tett (1998) (linear trend removed), C - multiproxy of Crowley and Lowery (2001) (linear trend removed), D - tree-ring proxy of Esper, Cook, and Schweingruber (2002), E - tree-ring proxy of Briffa (2000), F - non tree-ring proxy of Loehle (2007) (polynomial trend of the $4^{\text {th }}$ order removed), and G - multiproxy of Moberg, Sonechkin, Holmgren, Datsenko, and Karlen (2005) (polynomial trend of the $4^{\text {th }}$ order removed). All the spectra were calculated for AD 1000-1930.

These spectra show a more detailed picture of long-term global temperature variability. Even after removing the overall long-term trends none of the proxy records has a dominant 200-year cycle (Figure 3) and some of them have no bi-centennial temporal variation at all (see also Figure 4 in Ogurtsov, Lindholm, \& Jalkanen (2013)).

It should also be noted that in the forecast by Abdussamatov (2012), the greenhouse forcing was fully neglected. This approach needs to be seriously clarified, particularly taking into account that according to Abdussamatov $(2007$; 2012) TSI-the main climatic forcing factor - decreased continually since the end of the 1970s, while the actual global temperature had a sharp rise through this time interval. Even if we take into consideration the thermal inertia of the Earth with characteristic time 14 \pm 6 years (Abdussamatov, 2012), the increase of observed global mean temperature by $0.4-0.5^{\circ} \mathrm{C}$ during the years of $1978-2012$ seems to be in disagreement with the assumptions of Abdussamatov $(2007,2012)$.

However if we consider the greenhouse radiative forcing as a minor factor (as opposed to the IPCC view), the best way to make a climatic forecast is to use the paleoproxies as a source of information. Indeed, if global warming is mainly the result of natural climatic variability then climate in the $20^{\text {th }}$ century was driven by the same dynamic system as during the entire last millennium. This in turn means that the present state of climate is a natural result of its past and the paleoclimatic time-series could be used for prediction. In particular such temperature paleoproxies which have prevailing multi-centennial and millennial cycles would be more compatible with the assumption that the modern global warming is not unique in a historical context and this warming is caused by natural climatic cycles. Thus, a reasonable choice of data for performing predictions is to 
use the reconstructions of Loehle (2007) and Moberg, Sonechkin, Holmgren, Datsenko and Karlen (2005). A non-linear prediction was made by means of analogue method based on the reconstruction of trajectory of dynamical system of the forecasted series in pseudo-phase space - a modification of the method used by Sugihara and May (1990).

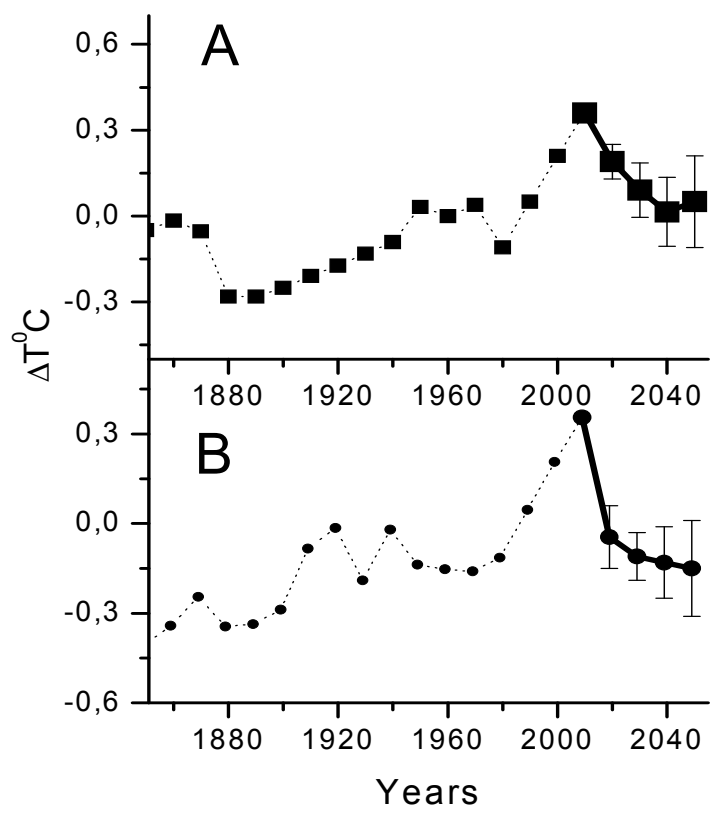

Figure 4. Forecasts of future Northern Hemisphere temperatures - Predictions based on reconstruction by A Loehle (2007) and B - Moberg, Sonechkin, Holmgren, Datsenko, and Karlen (2005). Both proxy series were extrapolated till 2010 by means of the instrumental temperature data. The original data, averaged by 13 years and interpolated by decades, are shown with dotted lines. Predicted values are shown with thick black lines.

The result of a nonlinear prediction based on temperature reconstructions of Loehle (2007) and Moberg, Sonechkin, Holmgren, Datsenko and Karlen (2005) show (Figure 4) (see also Figure 11 in Ogurtsov, Lindholm and Jalkanen (2013)) that if we practically ignore the greenhouse forcing, the forecasted mean temperature of the Northern Hemisphere in the first half of the $21^{\text {st }}$ century most likely will be lower than the modern value. Till 2050 it can drop by $0.3-0.5^{\circ} \mathrm{C}$, i.e. reach the level of the first part or mid- $20^{\text {th }}$ century, but not the values of the Little Ice Age. Further temperature projection does not become very informative due to increasing prediction errors. Thus, even in the framework of a rather unrealistic hypothesis of an insignificant greenhouse forcing, we did not get any evidence for the deep cooling over the first part of the current century. In addition, forecasts by other researchers, who considered man-made greenhouse warming to be less important than the IPCC assessment, have not shown substantial decrease in global temperature for the next few decades. Akasofu (2010) extrapolated observational data and predicted that global temperature till 2040 will be $0.1-0.2{ }^{\circ} \mathrm{C}$ lower than in 2010. Scafetta (2012), using instrumental data extrapolation, predicts mean global temperature to be $0.2-0.3{ }^{\circ} \mathrm{C}$ warmer by the middle of this century.

Obviously if global warming appears almost entirely as a result of man-made emissions of greenhouse gases, the corresponding climatic projections are reported by the IPCC. In the last report (IPCC, 2007) temperature was forecasted to rise between $1.8-4.0{ }^{\circ} \mathrm{C}$ in the $21^{\text {st }}$ century.

\section{Conclusion}

The currently available information, both instrumental and proxy, on global temperature change does not allow to predict a deep (more than $1{ }^{\circ} \mathrm{C}$ ) cooling during the $21^{\text {st }}$ century. The here discussed projections of Abdussamatov $(2007,2012)$ are based on:

(a) a number of either arbitrary or inaccurate assumptions;

(b) lack or ignorance of experimental data; and 
(c) a more or less flawed forecast technique.

The considered scientific evidence gives no reasons to anticipate the start of a new Little Ice Age in the next few decades.

\section{Acknowledgements}

M. G. Ogurtsov expresses his thanks to the exchange program between the Russian and Finnish Academies (project No. 16), and the RFBR grants Nos. 10-05-00129, 11-02-00755 and 13-02-00783 for financial support.

\section{References}

Abdussamatov, H. I. (2007). On decreasing a total irradiance and downturn of the global temperature of the Earth up to a global cooling in the middle XXI centuries. Bulletin of the Crimean Astrophysical Observatory, 103, 4, 292-298.

Abdussamatov, H. I. (2012). Bicentennial decrease of the Total Solar Irradiance leads to unbalanced thermal budget of the Earth and the Little Ice Age. Applied Physics Research, 4(1), 178-184. http://dx.doi.org/10.5539/apr.v4n1p178

Akasofu, S. I. (2010). On the recovery from the Little Ice Age. Natural Science, 2(11), 1211-1224. http://dx.doi.org/10.4236/ns.2010.211149

Briffa, K. R. (2000). Annual climate variability in the Holocene: interpreting the message of ancient trees. Quaternary Science Reviews, 19, 87-105. http://dx.doi.org/10.1016/S0277-3791(99)00056-6

Briffa, K. R., \& Osborn, T. J. (2002). Blowing hot and cold. Science, 295, 2227-2228. http://dx.doi.org/10.1126/science.1069486

Crowley, T. J., \& Lowery, T. S. (2000). How warm was the Medieval Warm Period? Ambio, 29, 51-54.

Dewitte, S., Crommelynck, D., Mekaoui, S., \& Joukoff, A. (2004). Measurement and uncertainty of the long-term total solar irradiance trend. Solar Physics, 224, 209-216. http://dx.doi.org/10.1007/s11207-005-5698-7

Esper, J., Cook, E. R., \& Schweingruber, F. H. (2002). Low-frequency signals in long tree-ring chronologies for reconstructing past temperature variability. Science, 295(5563), 2250-2253. http://dx.doi.org/10.1126/science.1066208

Fröhlich, C. (2006). Solar irradiance variability since 1978: revision of the PMOD composite during solar cycle 21. Space Science Reviews, 125, 53-65. http://dx.doi.org/10.1007/s11214-006-9046-5

Fröhlich, C. (2009). Evidence of a long-term trend in total solar irradiance. Astronomy and astrophysics, 501, L27-30. http://dx.doi.org/10.1051/0004-6361/200912318

Fröhlich, C. (2011). Total Solar Irradiance observations. Surveys in Geophysics, 33, 453-473. http://dx.doi.org/10.1007/s10712-011-9168-5

Haigh, J. D. (2009). Mechanisms for solar influence on the Earth's climate Climate and Weather of the Sun-Earth System (CAWSES): Selected Papers from the 2007 Kyoto Symposium. In T. Tsuda, R. Fujii, K. Shibata, and M. A. Geller (Eds.), Terrapub, Tokyo, 231-256.

Hoyt, D. V., \& Schatten, K. H. (1993). A discussion of plausible solar irradiance variations, 1700-1992. Journal of Geophysical Research, 98, 18895-18906. http://dx.doi.org/10.1029/93JA01944

Willson, R. C., \& Mordvinov, A. V. (2003). Secular total solar irradiance trend during solar cycles 21-23. Geophysical Research Letters, 30, 1199-1202. http://dx.doi.org/10.1029/2002GL016038

Jones, P. D., Briffa, K. R., Barnett, T. P., \& Tett, S. F. B. (1998). High-resolution palaeoclimatic records for the last millennium: interpretation, integration and comparison with general circulation model control-run temperatures. The Holocene, 8.4, 455-471. http://dx.doi.org/10.1191/095968398667194956

Kopp, G., \& Lean, J. L. (2011). A new, lower value of total solar irradiance: Evidence and climate significance. Geophysical Research Letters, 38, L01706, http://dx.doi.org/10.1029/2010GL045777

Krivova, N. A., Balmaceda, L., \& Solanki, S. K. (2007). Reconstruction of solar total irradiance since 1700 from the surface magnetic flux. Astronomy and Astrophysics, 467, 335-346. http://dx.doi.org/10.1051/0004-6361:20066725

Lean, J., Beer, J., \& Bradley, R. (1995). Reconstruction of solar irradiance since 1610:Implications for climate change. Geophysical Research Letters, 22, 3195-3198. http://dx.doi.org/10.1029/95GL03093 
Lockwood, M., \& Fröhlich, C. (2008). Recent oppositely-directed trends in solar climate forcings and the global mean surface air temperature: $\{\mathrm{II}\}$. Different reconstructions of the Total Solar Irradiance variation and dependence on response timescale. Proc. R. Soc. A, 464, 1367-1385. http://dx.doi.org/10.1098/rspa.2007.0347

Loehle, C. A. (2007). 2000-year global temperature reconstruction based on non-treering proxies. Energy and Environment, 18(7-8), 1049-1058. http://dx.doi.org/10.1260/095830507782616797

Mann, M. E., Bradley, R. S., \& Hughes, M. K. (1999). Northern Hemisphere temperatures during the past millennium: inferences, uncertainties, and limitations. Geophysical Research Letters, 26(6), 759-762. http://dx.doi.org/10.1029/1999GL900070

Moberg, A., Sonechkin, D. M., Holmgren, K., Datsenko, M. M., \& Karlen, W. (2005). High variable Northern Hemisphere temperatures reconstructed from low-and high-resolution proxy data. Nature, 433(7026), 613-617. http://dx.doi.org/10.1134/S0016793210080025

Mordvinov, A. V. (2010). Reduction of measurements of total solar flux to a unified scale and uncertainty in estimating its long-term trends. Geomagnetism and Aeronomy, 50(8), 933-936. http://dx.doi.org/10.1134/S0016793210080025

Ogurtsov, M. G. (2009). Prediction of cycle 24 based on information about solar activity during the last 10000 years. Geomagnetism and Aeronomy, 49(3), 408-411. http://dx.doi.org/10.1134/S0016793209030165

Ogurtsov, M., Lindholm, M., \& Jalkanen, R. (2013). Global warming - scientific facts, problems and possible scenarios. Manuscript submitted for publication.

Scafetta, N. (2012). Testing an astronomically based decadal-scale empirical harmonic climate model versus the IPCC (2007) general circulation climate models. Journal of Atmospheric and Solar-Terrestrial Physics, 80, 124-137. http://dx.doi.org/10.1016/j.jastp.2011.12.005

Solanki, S. K., \& Fligge, M. (1999). A reconstruction of total solar irradiance since 1700. Geophysical Research Letters, 26(16), 2465-2468. http://dx.doi.org/10.1029/1999GL900370

Sugihara, G., May, R. M. (1990). Nonlinear forecasting as a way of distinguishing chaos from measurement error in time series. Nature, 344, 734-741. http://dx.doi.org/10.1038/344734a0

Usoskin, I. G. (2008). A history of solar activity over millennia. Living Rev. Sol. Phys., 5(3). http://dx.doi.org/10.12942/lrsp-2008-3 